\title{
BEING POSITIVE. APPROACHING CAREER DESIGN FROM THE PERSPECTIVE OF POSITIVE PSYCHOLOGY
}

\author{
Matgorzata KlimKa \\ Institute of Applied Psychology, University of Social Sciences, \\ ul. Sienkiewicza 9, 90-113 Lodz, Poland \\ mklimka@san.edu.pl \\ GraŻYNA BudZIŃSKA \\ Institute of Applied Psychology, University of Social Sciences, \\ ul. Sienkiewicza 9, 90-113 Lodz, Poland \\ grazyna.budzinska2@gmail.com
}

\begin{abstract}
Constructing a career path based upon positive personal potential and positive individual resources is a significant factor for professional development of employees and their success on today's labour market. A satisfying career, an inherent element of personal well-being and good life, is linked with an ability to explore and reinforce signature strengths. In order to effectively design programmes which could support young people who are preparing to enter a job market, it is essential to acquire knowledge about values and character strengths and their perceptions among young people living in Poland and abroad. The article presents comparative analysis of signature strengths perceptions among young people in different cultures and discusses the significance of the most striking differences.
\end{abstract}

Keywords: Career design, positive psychology, strength, virtues

\section{INTRODUCTION}

The article aims to show positive psychology and its role in constructing a career path in the case of young people preparing to enter a job market. Martin Seligman (2011), a leading representative of positive psychology, indicates that subjective well-being depends on positive emotions, engagement, meaning, positive relations with others and achievements. The above mentioned aspects are treated by Seligman as measures of subjective well-being, which is impossible to achieve without its specific activators namely virtues and signature strengths (Seligman, 2005). The assumption that happiness arises from recognizing our positive attributes and using them while working, loving, playing and raising children (Seligman 2005, 15) gave a beginning to a discourse on the salience of virtues and signature strengths for constructing a career path by young people who are preparing for a job. The discourse seems especially important in the context of intensive changes that can be observed in career counselling in the times 
of quick transformations on the job market, precariousness of work, appearance of new professions and numerous jobs becoming obsolete on an everyday basis. According to Mark Savickas individuals are obliged today not only to choose a specific career and sustain it but they also have to project and construct their lives and careers in such a way as to increase their employability and competitiveness on a job market (Minta 2012). The article presents the results of research whose goal was to conclude about the importance of the virtue and signature strength conditioned well-being for job satisfaction and success. Additionally, the authors posed a question about the impact of optimism on job satisfaction and attempted to measure the difference in perceptions of signature strengths and virtues a well as the difference in perceptions of the importance of optimism on career construction in two groups of young people: students born and raised in Poland and foreign students who are studying in Poland for the period of six months within Erasmus exchange programme.

\section{THE WORLD OF WORK AND ITS IMPACT ON CAREER DESIGN}

The world of work has been changing constantly together with the changes in economy and technology. In order to be sustainable and successful on the market companies have to develop strategies to react quickly and gain competitive advantage over their rivals. The nature and quality of decision-making processes in competitive companies depend on the people they employ, the people who, in fact, constitute a core of competitive advantage. Thus, fast changes in economy are transferred onto the employees responsible for an ability of a company to react to the often unexpected requirements of the global business environment "to be 'lean and mean' and restructure continually" (Sweet, Meiksins 2013, 91-96).

Continuous changes in the economy and market realities transform the nature of the labour market, make it more unstable and insecure, and challenge people with "employment relations in transitions" (Kallenberg 2009, pp.1-22) characterized by a constant flow and precariousness. That is why it is difficult for people to predict or plan the future life and future career. The concept of liquid societies created by Zygmunt Bauman (2007, pp. 2 - 4) seems to be adequate to the world of today since permanent change and instability are the only elements of today's life and work that appear to be unquestionable. Social structures based on long-term planning and acting are no longer a major part of our experience and that is why individual lives consist of a series of short-time projects rather than of one coherent and planned sequence. What is more, these tendencies are transferred from country to country thanks to globalization processes. Precarious work seems to be pervasive today and as such it demands new approaches to life and career design that could supplement well-known and established models. The concepts of Milton Erikson's identity development, Donald Super's career planning or vocational personalities advocated by John Holland refer to more stable and predictable modes of career and personal development and seem not to be adequate in the reality characterized by a constant and unstable change and extreme needs 
for adaptability. In liquid societies an individual has to react to a changing reality of life and work and construct his life and a career while looking for the best personal-organizational fit in a constantly changing context.

\section{VIRTUES AND CHARACTER STRENGTHS AS A BASIS OF GOOD LIFE AND WORK}

Centrality of work in life cannot be questioned or underestimated, especially if we take into consideration how much work conditions psychological, social and economic aspects of life. That is why the fit between a person and his or her job has been long sought by career counsellors. This article would like to propose an approach to career design and development of person-job fit based on positive psychology and character strengths. Positive psychology brought back attention to character as an important basis of psychological good life of an individual but also societal well-being (Peterson, 2006). Martin Seligman and Mihaly Csikszentmihalyi (2000, pp. 5-14) presented a study of positive traits as core in positive psychology. The notion of eudaimonia borrowed from Aristotle let Martin Seligman (2002) advocate that good life and happiness are based on signature strengths identified and used extensively in acting by a person, in his life and obviously at the workplace. Nansook Park and Christopher Peterson (2003, pp. 33-47) linked positive traits to positive experiences, social relations and positive organizations.

\section{Virtues}

The classification of character strengths is known as the Values In Action project since the VIA Institute supported financially the introduction of the project. The classification is based upon 24 character strengths grouped under 6 virtues. Good character is perceived as a family of characteristics that exist in different proportions, some people having less or more of a given character strength. A virtue was understood based on the definition following the field of virtue ethics (Yearly, 1990), which, in fact is close to the meaning of a trait presented in personality psychology as "a disposition to act, desire and feel that involves the exercise of judgment and leads to a recognizable human excellence or instance of human flourishing". Moreover, virtuous activity involves choosing virtue for itself and in the light of some justifiable life plan.

Similar to personality traits, virtues constitute character which is, however, treated as more specific than personality: it is like personality but evaluated morally. (Baumrind 1998, pp.1-28). Based on the review of philosophical and religious traditions, the researchers identified a set of six virtues. They are important in majority of the above-mentioned traditions (Dahlsgaard, Peterson, \& Seligman, 2005) and as such were treated as a basis for character strengths:

- Wisdom and knowledge are understood as cognitive strengths and are necessary to acquire knowledge and use it.

- Courage, which is emotional in its nature and is understood as a will to attain goals in the context of internal or external opposition. 
- Humanity, which is interpersonal in its nature, and is connected with befriending others.

- Justice, which is civic in its nature, and constitutes the basis of community well-being.

- Temperance, which protects people from excessive actions.

- Transcendence, which connects an individual to the world beyond himself and provide him with meaning.

\section{Character Strengths}

In the process of character strength classification under the above-mentioned specific virtues researchers identified a set of criteria to verify if a strength is to be taken into consideration. The strength should be widely recognized across cultures (ubiquity), contribute to individual happiness and fulfilment (fulfilling), should have moral value in itself and should evoke admiration when noticed by others, should have an easily identifiable antonym and has been measured and examined as an individual difference. What is more, it is distinctive and not redundant in the collection of the whole set of strengths and it has paragons vividly embodying the strength. It can be early represented in some children and young people but also missing in other persons as well as it is deliberately cultivated by some institutions as a desired social target.

Character strengths were evaluated with the use of a variety of measures such as focus groups, structured interviews, reports of how target persons used a specific character strength on a particular occasion, content analysis for assessing unstructured descriptions, case studies on the behaviours of paragons of specific strengths. The measures for adults were designed and developed based on the group of mature persons who "have done more than rehearse work and love" (Peterson , Park 2011, pp. 54 - 55). One million respondents from fifty US states and two hundred different nations participated in an on-line study. That is why we may conclude that virtues and character strengths reflect verified perceptions salient for work and life satisfaction.

Character strengths were organized conceptually by researchers under given virtues and, as presented below, do not reflect an empirical picture. Selected character strengths may be more represented in some cultures and not so very representative for other cultures or there can be some strengths bonded with a specific culture but not used in the classification because not present in other cultures and as such not complying with the ubiquity criterion. As researchers suggest some strengths could play more important role in careers if they go together with other strengths, their individual impact might not be, then, so predominant. Generally, the researchers see a real need to study strengths configurations and potentially implement changes into the classification presented in the table below (Peterson, Park 2011, pp. 49 - 62). 


\section{THE VIA CLASSIFICATION OF STRENGTHS}

- Wisdom and Knowledge

- Creativity: thinking of novel and productive ways to conceptualize and do things; includes artistic achievement but is not limited to it.

- Curiosity: taking an interest in ongoing experience for its own sake.

- Open-mindedness: thinking things through and examining them from all sides.

- Love of learning: mastering new skills, topics, and bodies of knowledge.

- Perspective: being able to provide wise counsel to others.

- Courage

- Honesty: speaking the truth but more broadly presenting oneself in a genuine way and acting in a sincere way. Bravery: not shrinking from threat, challenge, difficulty, or pain.

- Persistence: finishing what one starts; persisting in a course of action in spite of obstacles; taking pleasure in completing tasks.

- Humanity

- Zest: approaching life with excitement and energy.

- Love: valuing close relations with others, in particular those in which sharing and caring are reciprocated; being close to people.

- Kindness: doing favours and good deeds for others; helping them; taking care of them.

- Social intelligence: being aware of the motives and feelings of other people and oneself.

- Justice

- Fairness: Treating all people the same according to notions of fairness and justice.

- Leadership: organizing group activities and seeing that they happen.

- Teamwork: working well as a member of a group or team; being loyal to the group; doing one's share.

- $\quad$ Temperance

- Forgiveness: forgiving those who have done wrong.

- Modesty: letting one's accomplishments speak for themselves; not regarding oneself as more special than one is.

- Prudence: being careful about one's choices, not saying or doing things that might later be regretted.

- Self-regulation: regulating what one feels and does; being disciplined; controlling one's appetites and emotions.

- Transcendence

- Appreciation of beauty and excellence: noticing and appreciating beauty, excellence, and/or skilled performance in various domains of life.

- Gratitude: being aware of and thankful for the good things that happen; taking time to express thanks. 
- Hope: expecting the best in the future and working to achieve it.

- Humour: liking to laugh and tease; bringing smiles to other people.

- Spirituality: having coherent beliefs about the higher purpose and meaning of life.

\section{THE AIM OF THE STUDY}

The aim of the study was to determine which virtues Polish and foreign students deem important for building a professional career, and discover whether Polish students have a similar outlook on the importance of virtues and character strengths as international students. What is more, the study aims to present comparison between perceptions in the group of Polish and international students concerning the level of positive orientation or optimism, self-esteem, life satisfaction and job satisfaction, which includes an element of satisfaction from studies. It is assumed that the representation of certain virtues contributes to a better, happier life which leads to a conclusion that those virtues can be treated as predictors of positive orientation and positive job satisfaction understood as satisfaction from the career path, which can include satisfaction from studies in the chosen field.

During the process of research, the following research questions were developed:

1. Which virtues are important for students?

2. Are there differences in perceptions of the importance of specific virtues for successful career between Polish and foreign students taking their education in Poland?

3. Are there differences between Polish and foreign students concerning the level of positive orientation?

4. Are there differences between Polish and foreign students referring to the level of job satisfaction?

5. Can the analysed virtues be predictors of a positive orientation and job satisfaction?

\section{THE STUDY GROUP}

The study group consisted of 135 people, both women and men. The above includes 32 foreign students studying in Poland for one semester within Erasmus exchange programme and 103 students born and raised in Poland. The Polish and foreign students represented various fields of studies including technical studies, social sciences, humanistic and medical studies. The average age of the students of Polish origin is 26.4, the average age of foreign students is 22.3. 


\section{DESCRIPTION OF THE RESEARCH METHOD}

\section{The scale of positive orientation}

The first scale used in the study was the Positivity Scale by Gian Vittorio Caprara, Guido Alessandri; Nancy Eisenberg, Anna Kupfer, Patrizia Steca, Maria Giovanna Caprara, Susumu Yamaguchi, Ai Fukuzawa, John Abela, The research of the Polish group was based on the positive orientation scale adapted by Mariola Łaguna, Piotr Oleś, Dorota Filipiuk. The tool consists of eight diagnostic questions. The person examined addresses the eight items using a five-point scale, where 1 means that the respondent totally disagrees with the statement and 5 means full agreement. The tool is used to measure the positive orientation as the structure that takes into account self-esteem, optimism and life satisfaction. The authors of the Polish version of the scale analysed the psychometric properties and concluded that psychometric properties are sufficient.

\section{Job satisfaction scale}

The scale of job satisfaction developed by Anna Zalewska is composed of five statements to which the respondent shall respond using a seven-point scale, where 1 is equivalent to not agreeing with the statement and 7 means that the respondent strongly agrees with the item. The tool is used to test the overall level of job satisfaction, and its structure and content was inspired by the Satisfaction with Life Scale (SWLS) by Ed Diener. The scale has sufficient psychometric properties.

\section{THE SURVEY TO EXAMINE THE IMPORTANCE OF VIRTUES AND SIGNATURE STRENGTHS - MAŁGORZATA KLIMKA, GRAŻYNA BUDZIŃSKA}

The last tool used in the study was a survey examining the importance of virtues and signature strengths.

For the analysis, the authors used a survey constructed on the basis of the CSV list of Character Strengths and Virtue (Peterson, Seligman, 2004) developed under the direction of Christopher Peterson. In that survey, respondents were asked to analyse the listed virtues and character strengths according to their importance in their careers.

In the first part of the questionnaire, respondents were instructed to assess the importance of each virtue on the following scale: 1 - very important, 2 - rather important, 3 - no opinion, 4 - rather unimportant, 5 - not important. In the second part of the survey respondents were asked to estimate which of the values is the most important in their careers. A scale from 1 to 6 was used, 1 being the most important and 6 being the least important. In addition, the survey contained questions about age, gender, education, and marital status, place of residence, employment status and developing professional skills by persons surveyed. 


\section{STUDY RESULTS}

\section{Perception of the importance of virtues.}

The group of Polish students identified wisdom and knowledge as the most important virtues for building a career, those were followed by courage, humanity, justice, temperance, and transcendence identified as the least important for career development.

\section{Descriptive statistics}

\begin{tabular}{|l|l|l|l|l|l|}
\hline & N & Min. & Max. & Mean & $\begin{array}{l}\text { Std. } \\
\text { deviation }\end{array}$ \\
\hline Transcendence & 103 & 1 & 6 & 5,51 & 1,110 \\
Temperance & 103 & 1 & 6 & 4,12 & 1,123 \\
Justice & 103 & 1 & 6 & 3,28 & 1,403 \\
Humanity & 103 & 1 & 6 & 3,11 & 1,342 \\
Courage & 103 & 1 & 6 & 2,85 & 1,263 \\
Wisdom and knowledge & 103 & 1 & 6 & 1,64 & 1,074 \\
Valid N (list wise) & 103 & & & & \\
\hline
\end{tabular}

Table 1. Importance of virtues in the perception of Polish students Source: Own analysis

Foreign students identified wisdom and knowledge as the most important virtues, followed by courage, humanity, justice, transcendence and temperance.

\section{Descriptive statistics}

\begin{tabular}{|l|l|l|l|l|l|}
\hline & N & Min. & Max. & Mean & $\begin{array}{l}\text { Std. } \\
\text { deviation }\end{array}$ \\
\hline Temperance F & 32 & 2 & 6 & 5,00 & 1,107 \\
Transcendence F & 32 & 2 & 6 & 4,16 & 1,322 \\
Justice F & 32 & 2 & 6 & 3,66 & 1,558 \\
Humanity F & 32 & 1 & 6 & 3,41 & 1,365 \\
Courage F & 32 & 1 & 6 & 3,19 & 1,857 \\
Wisdom and knowledge F & 32 & 1 & 6 & 1,97 & 1,513 \\
Valid N (list wise) & 32 & & & & \\
\hline
\end{tabular}

Table 2. Importance of signature strengths in the perception of foreign students. Source: Own analysis

The performed univariate analysis of variance ANOVA revealed that statistically significant differences between the two groups can be observed in temperance and transcendence. Polish students perceived temperance as more important than foreign students. Transcendence was seen as the least important virtue by Polish students, foreign students determined that it is a more important virtue than temperance. 


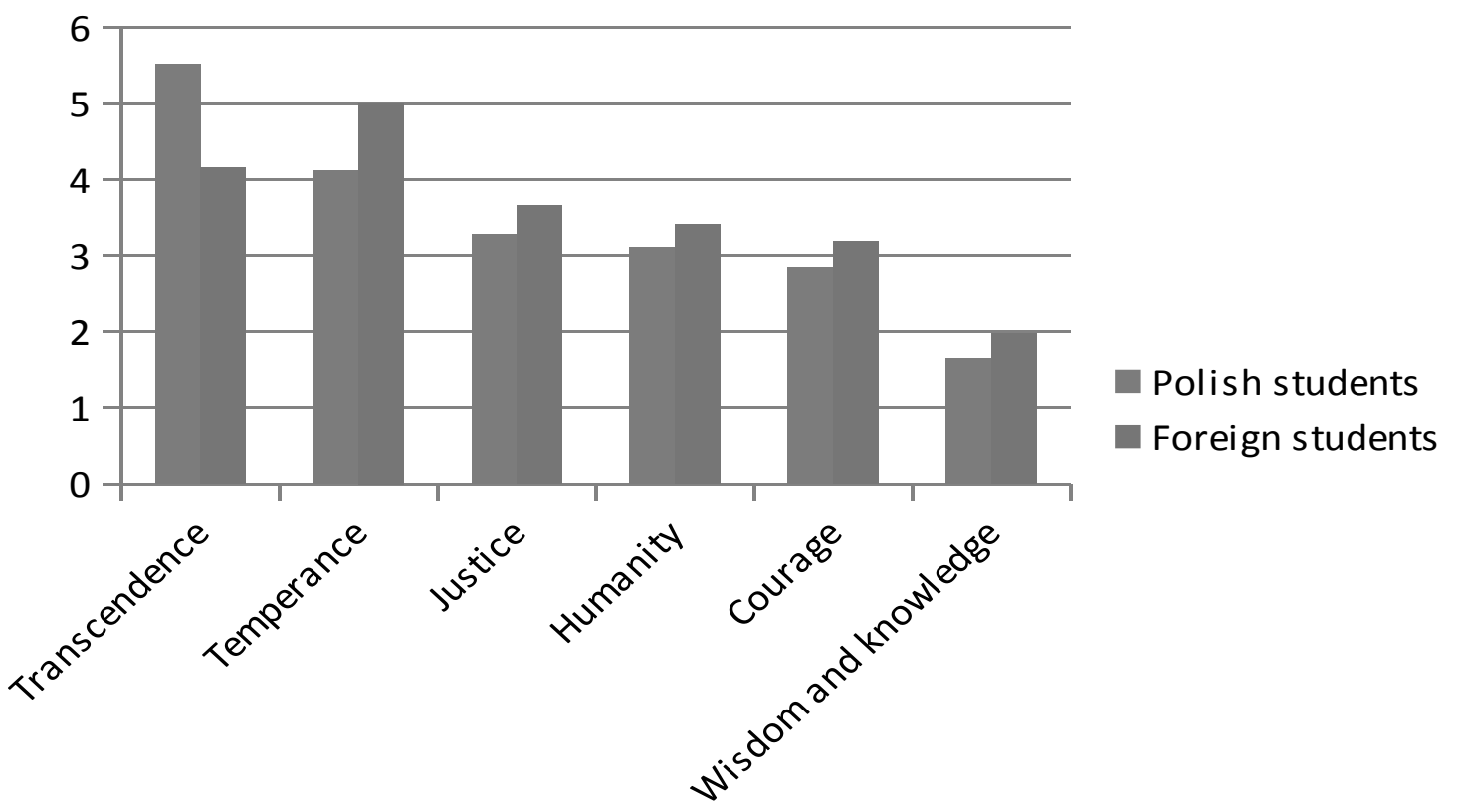

Fig 1. Comparison of perception of virtues important for career development for Polish and foreign students.

Source: Own analysis

\section{Level of positive orientation}

The performed univariate analysis of variance showed that the compared groups differ significantly. The group of Polish students represents a higher level of positive orientation.

\section{Descriptive statistics}

\begin{tabular}{|l|l|l|l|l|l|}
\hline & N & Min. & Max. & Mean & $\begin{array}{l}\text { Std. } \\
\text { deviation }\end{array}$ \\
\hline Scale P & 103 & 3 & 10 & 6,14 & 1,408 \\
Scale PF & 31 & 4 & 9 & 7,19 & 1,447 \\
Valid N (list wise) & 31 & & & & \\
\hline
\end{tabular}

Table 3. Average level of positive orientation in the compared groups.

Source: Own analysis

\section{Job satisfaction level}

The univariate analysis of variance ANOVA showed that the studied groups differ significantly. Foreign students represent a higher level of job satisfaction and satisfaction in building a career path in which studies are included.

Descriptive statistics

\begin{tabular}{|l|l|l|l|l|l|}
\hline & N & Min. & Max. & Mean & $\begin{array}{l}\text { Std. } \\
\text { deviation }\end{array}$ \\
\hline Job satisfaction & 103 & 6 & 31 & 19,50 & 5,719 \\
Job satisfaction F & 32 & 16 & 30 & 22,16 & 3,548 \\
Valid N (list wise) & 32 & & & & \\
\hline
\end{tabular}

Table 4. Average level of job satisfaction in the compared groups.

Source: Own analysis 


\section{Predictors of positive orientation}

Positive orientation was adopted as a dependent variable, while wisdom and knowledge, courage, justice, temperance, humanity and transcendence as independent variables and a linear regression analysis was performed. It was found that in the case of the test group there are two predictors of positive orientation and these are transcendence and humanity.

Fig. 2. Predictors of positive orientation in the test group.

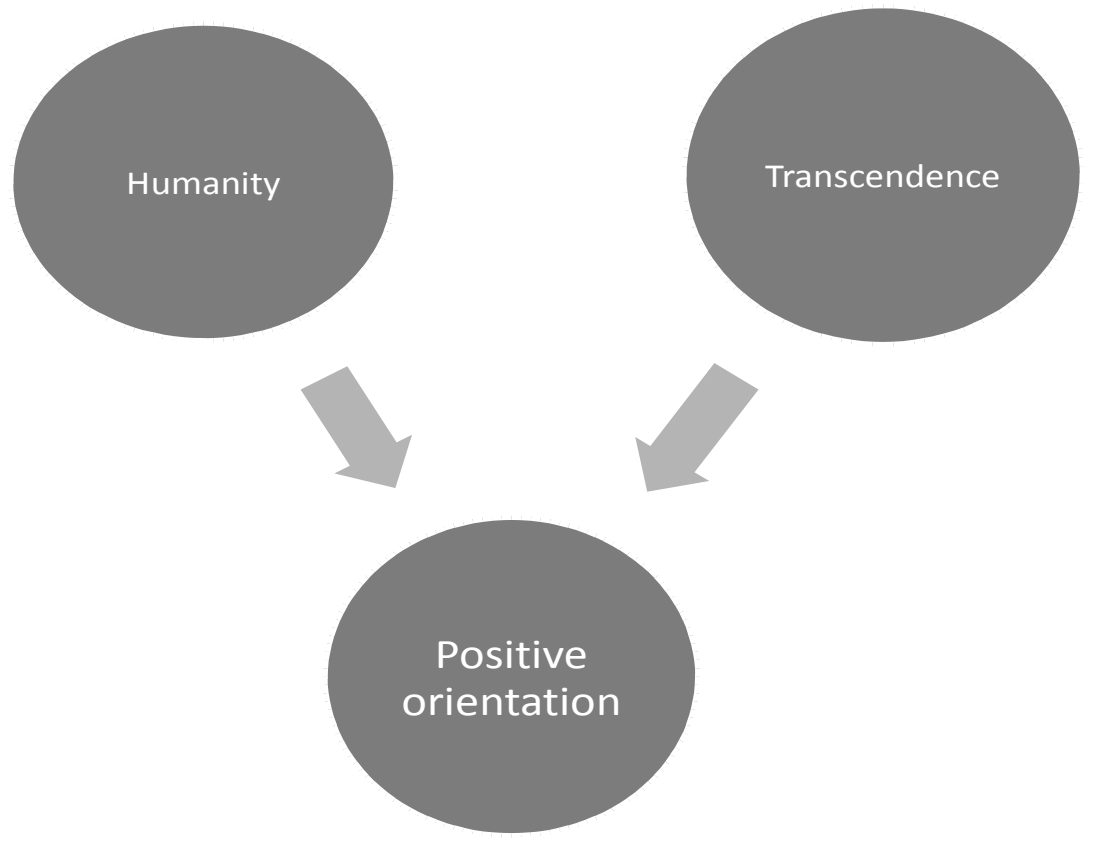

Source: Own analysis

The linear regression analysis, in which job satisfaction was assumed as a dependent variable while wisdom and knowledge, courage, justice, temperance, humanity and transcendence as independent variables, did not show that the independent variables were predictors of job satisfaction for the test group of Polish and foreign students.

\section{CONCLUSIONS}

The analysis presented above lets us draw a conclusion that the development of virtues and signature strengths are salient for building a career path by young people. Young people manifest a need for a complex development of formal and personal competencies. Both foreign and Polish students value wisdom and knowledge highly whereas the lowest appreciation is shown towards transcendence and temperance. Nevertheless, the latter virtues are not categorized as unimportant but relatively less important and that is why they are placed at the bottom of the hierarchy of values. Ranking temperance and knowledge low as compared with other virtues might result from the lack of understanding of the meaning of abovementioned values or the lack of experience on the job market. 
Polish students generally perceive the development of virtues and signature strength as important for career building. However, they represent lower level of positive orientation and job satisfaction than foreign young people. Taking into consideration the results of the conducted research we may conclude that transcendence and humanity are predictors of positive orientation and that is why further analysis should be conducted in order to explore the relation between those virtues and positive orientation, and to find more precise reasons for different perceptions of humanity and transcendence in the groups of Polish and foreign students. The analysis was not able to prove any relation between job satisfaction and the perceptions of virtues, which seems to be a subject worth further examination.

Summing up, it may be concluded that the most important result of the analysis is the appreciation of virtues and their importance for the satisfying career construction among young people, no matter what ethnic group they come from. Polish students may be less positively oriented and may express lower job satisfaction due to poor economic situation in their country or due to cultural differences that have impact on attitudes and expectations. That is why, it seems important to focus more, in Poland, on the development of programmes which would target personal competencies acquisition and could support young people in increasing their self-esteem as well as in developing more optimistic orientation. The programmes should go beyond the major focus students choose in their university studies because this broader orientation would help young people to build universal values for life and work based on wisdom, knowledge, courage, humanity, transcendence, temperance and justice.

\section{REFERENCES}

Bauman, Z. (2007). Liquid Times: Living in an Age of Uncertainty. Cambridge, Polity Press, 2-4.

Baumrind, D. (1998). Reflections on character and competence. In: A. Colby, J. James, \& D. Hart (Eds.), Competence and character through life. Chicago: University of Chicago Press, 1 - 28

Dahlsguard, K., Peterson, C., \& Seligman, M.E.P. (2005). Shared virtue: the convergence of valued human strengths cross culture and history. Review of General Psychology, 9, 209-2013.

Kalleberg, A. L. (2009). Precarious Work, Insecure Workers: Employment Relations in Transition. American Sociological Review, 74, 1-22.

Minta, J. (2011). Od aktora do autora. Wspieranie młodzieży w konstruowaniu własnej kariery. Warszawa: Krajowy Ośrodek Wspierania Edukacji Zawodowej i Ustawicznej, 1 - 116.

Park, N., \& Peterson, C. (2003). Virtues and Organizations. In: K.S. Cameron, J.E. Dutton, \& R.E. Quinn (Eds.), Positive organizational scholarship: Foundations of a new discipline. San Francisco: Bernett-Koehler, $33-47$.

Peterson, C. (2006). A Primer in Positive Psychology. New York: Oxford University Press.

Peterson, Ch., Park,N. (2011). Character Strengths and Virtues. Their Role in Well-being. In: S.I. Donaldson, M. Csikszentmihalyi \& J. Nakamura (Eds.), Applied Positive Psychology: Improving Everyday Life, Health, Schools, Work, and Society. New York: Routledge, 54 - 55

Peterson, Ch.,Park, N. (2011). Character Strengths and Virtues. Their Role in Well-being. In: S.I. Donaldson, M. Csikszentmihalyi \& J. Nakamura (Eds.), Applied Positive Psychology: Improving Everyday Life, Health, Schools, Work, and Society. New York: Routledge, 49 - 62

Seligman, M. E. P. (2002). Authentic Happiness. New York: Free Press, 1 - 305

Seligman, M. E. P. (2005). Prazdzize szczęście. Poznań: Media Rodzina, 1 - 320

Seligman, M. E. P. (2011). Pełnia życia. Nowe spojrzenie na kwestię szczęścia i dobrego życia. Poznań: Media Rodzina, 1 - 430 
Seligman, M.E. P., \& Csikszentmihalyi, M. (2000). Positive Psychology. An Introduction. American Psychologist, 55, 5-14.

Sweet, S., Meiksins, P. (2013). Changing Contours of Work: Job and Opportunities in the New Economy. New Delhi: Sage Publications, 91-96.

Yearly, L.H. (1990). Mancius and Aquinas: Theories of virtue and conception of courage. Albany, N.Y.: State University of New York Press. 